\title{
The Effect of Contextual Clues and Topic Familiarity on L2 Lexical Inferencing and Retention
}

\author{
SHIVA KAIVANPANAH \\ University of Tehran \\ NiLOOFAR RAHIMI \\ University of Tehran \& University of Nottingham, UK
}

Received: 1 October 2015 / Accepted: 23 April 2016

ISSN: 1697-7467

\begin{abstract}
The present study examined the effect of contextual clues and topic familiarity on L2 lexical inferencing success and retention. To this end, 67 Iranian EFL learners read stories (cue-adequate contexts varying in degree of familiarity) and single sentences (cueinadequate contexts) including unknown lexical items and inferred the meaning of unknown words. Subsequently, they were tested on those words once immediately and once after two weeks. Results revealed an inferencing success rate of $55.76 \%$, with success being significantly affected by the amount of contextual clues and topic familiarity. Moreover, it was found that although the effect of context on word meaning retention lasted for two weeks, the effect of topic familiarity decreased over time. Also, think-aloud protocols were used to identify main reasons leading participants to make incorrect inferences. The findings imply that lexical inferencing should be practiced in texts with adequate cues.
\end{abstract}

Keywords: contextual clues, lexical inferencing, topic familiarity.

\section{El efecto de pistas contextuales y familiaridad de tema en la inferencia y la retención} léxica del L2

RESUMEN: El presente estudio tiene como el objetivo estudiar el efecto de las pruebas contextualizadas así como los tópicos familiarizados en la inferencia del léxico de L2 y también su retención. Para este fin, fueron estudiados 67 estudiantes iraníes de Inglés, L2 (muestras adaptadas al contexto variando el grado de familiarización) y oraciones simples (muestras no adaptadas al contexto) incluyendo los léxicos desconocidos, deduciendo el significado de las palabras desconocidas. El resultado revelaba: a) una taza de inferencia de $55.76 \%$, b) el efecto de la cantidad del contexto así como los tópicos familiarizados en la inferencia lexical, c) el efecto de tiempo en el conocimiento de las palabras inferidas. d) factores principales que terminan en la inferencia incorrecta de las palabras objeto de estudio. Palabras claves: leer, inferencia lexical de L2, tópicos familiarizados, pruebas contextualizadas.

\section{INTRODUCTION}

Lexical inferencing is defined as "making informed guesses as to the meaning of an utterance in light of all available linguistic cues in combination with the learner's general 
knowledge of the world, her awareness of context and her relevant linguistic knowledge" (Haastrup, 1991: 40). Researchers have been interested in lexical inferencing as it is considered the most commonly used and preferred strategy in dealing with unknown words among readers (e.g., Fraser, 1999; Kaivanpanah \& Alavi, 2008a; Laufer, 1997; Paribakht, 2004; Paribakht \& Wesche, 1999; Qian, 2005). The assumption underlying the benefit of using lexical inferencing strategy is that not only does it help readers comprehend texts, but also it leads to improvement of their vocabulary knowledge as it involves some mental effort for processing a word (Haastrup, 1991; Nassaji \& Hu, 2012).

Research on lexical inferencing has identified reader-based and text-based factors that contribute to lexical inferencing success. Reader-based factors involve vocabulary knowledge (e.g., Paribakht, 2005), knowledge of grammar (e.g., Kaivanpanah \& Alavi, 2008b; Paribakht, 2004), language proficiency (e.g., Barnett, 1989), attention to details (e.g., Laufer, 1997), cognitive and mental effort (e.g., Fraser, 1999; Paribakht \& Wesche, 1999), and readers' characteristics (e.g., Paribakht, 2005) such as their background knowledge, interest, familiarity with topic, and previous learning experiences. Text-based factors include word characteristics (e.g., Mondria \& Wit-de Boer, 1991), text characteristics (e.g., Paribakht \& Wesche, 1999; Frantzen, 2003), and the presence of contextual clues (e.g., Liu \& Nation, 1985; Paribakht \& Wesche, 1999).

Among these factors, the focus of the present study is on readers' familiarity with topic (reader-based factors) and contextual clues in the text (text-based factors). Although these factors significantly influence lexical inferencing, few studies have examined the effect of combination of these variables, i.e., presence of varying contextual clues and familiarity with the text topic on lexical inferencing and retention of the inferred words' meaning over time (e.g., Li, 1988; Mondria \& Wit-de Boer, 1991; Tavakoli \& Gerami, 2013). The results of such studies would provide useful information for teachers and materials developers as to the types of texts which would effectively promote learners' lexical inferencing ability. Therefore, the present study aims to examine lexical inferencing success of L2 readers and determine the extent to which their success is affected by the presence of contextual clues in the text and topic familiarity. In addition, by employing think-aloud protocols, this study attempts to identify factors which might guide readers to make incorrect inferences.

\section{Literature REVIEW}

\subsection{Lexical inferencing success rate in $\mathrm{L2}$}

Several studies have indicated that learners are able to successfully infer the meaning of unfamiliar words while reading texts. For example, readers in Huckin and Bloch's (1993) study could guess the meanings of $56.8 \%$ of the unfamiliar words correctly and $54 \%$, on average, in Morrison's (1996) study. Also, different rates of inferencing success have been reported in other studies; the inferencing success rate was $41 \%$ in Bengeleil and Paribakht's (2004) study, 45\% in Qian's (2005) study, 56\% in Pulido's (2007) study and 59\% in Hu and Nassaji's (2012) study. However, Nassaji (2003) and Paribakht and Wesche (2010) found that participants in their study achieved a rather low lexical inferencing rate of $25.6 \%$, and $21 \%$ respectively. As seen, although readers' lexical inferencing success rate varies depending 
on factors such as participants' characteristics, types of materials used, and scoring systems deployed, on average, readers can successfully infer the meaning of unfamiliar words by $50 \%$. To shed more light on this issue, the effects of contextual clues and topic familiarity on lexical inferencing success rate will be discussed in what follows.

\subsection{Effects of contextual clues on L2 lexical inferencing}

Research has shown that quality of the text in which unknown words are embedded has a significant impact on learners' lexical inferencing behavior (e.g., Li, 1988; Huckin \& Bloch, 1993; de Bot, Paribakht \& Wesche, 1997; Paribakht \& Wesche, 1999). Text quality depends on the availability of contextual clues which refer to the presence of clear and sufficient input information (both semantic and linguistic) surrounding the unknown words that give clues about the meaning of these words when reading a text (Haastrup, 1991).

Generally, there are two types of contextual clues for lexical inferencing: local clues which refer to the clues in the same sentence or in the previous/next sentence of the unknown word, and global clues which refer to clues found beyond the sentence containing unknown words (Huckin \& Bloch, 1993). Van Parreren (1967 cited in Mondria \& Wit-de Boer, 1991: 252) referred to a so-called "pregnant context" which provides adequate clues (local \& global) to make the meaning of unknown words inferable, noting that "the more pregnant the context is, the easier it is to guess the word". This claim can come from the default inferencing type in schema theory (Anderson \& Pearson, 1984 cited in Nassaji, 2002), suggesting that clues in the text can activate a certain schemata in readers' memory which can in turn help them successfully infer the meaning of unfamiliar words. Thus, availability of adequate contextual clues in the text has a significant role in helping readers to arrive at correct meaning of the unknown words. This has been supported by a growing body of research in the field of lexical inferencing. For example, Li's (1988) study revealed that participants in cue-adequate contexts had greater ease in guessing the meaning of unfamiliar words. Similarly, Mondria and Wit-de Boer's (1991) study suggested that sentences with more clues encouraged more successful lexical inferencing by readers. In a more recent study by Çetinavcı (2014), similar results were obtained: the presence of unknown words in a rich-clue context enabled participants to infer their meaning more successfully than in a poor-clue context. Likewise, in Hu's (2013) case study, it was found that contextual richness had a significant impact on the acquisition of form-meaning connections in reading English texts. Using think-aloud protocols, Comer (2012) found that readers frequently use contextual clues to make successful lexical inferences.

Despite the fact that learners use context to infer the meaning of unknown words while reading, research indicates that there are limitations on the value of context (e.g., Dubin \& Olshtain, 1993; Huckin \& Bloch, 1993; Hulstijn, 1992; Laufer, 1997; Parry, 1993). Contexts sometimes are ambiguous or do not always provide adequate information about the meaning of unfamiliar words, thereby they do not direct readers to make accurate lexical inferences. Hence, no general conclusion exists in the literature over the usefulness of contextual clues for lexical inferencing. For example, Frantzen (2003) argues that readers in her study, in some cases, failed to make correct inferences when the context was misleading. Therefore, specific learning outcomes in utilizing context for successful lexical inferencing strategy are unpredictable, and further research examining the role of contextual clues in lexical inferen- 
cing success is required to shed light on whether context can induce successful inferencing and subsequent long-term retention of the meaning of inferred words.

\subsection{Effects of topic familiarity on L2 lexical inferencing}

The role of topic familiarity in lexical inferencing has been addressed in a number of studies (e.g., Nassaji, 2003; Paribakht \& Wesche, 1999; Pulido, 2004, 2007). Topic familiarity refers to readers' background knowledge of and their level of familiarity with the topic and content of a text, which influences their comprehension and ability to make correct inferences (e.g., Chern, 1993; Nassaji, 2003; Paribakht \& Wesche, 1999). Nassaji (2003) maintained that background knowledge facilitates comprehension as the information generated from script-based texts acts as a signal activating the stored knowledge in longterm memory which can in turn promote better text comprehension. Thus, comprehension is enhanced when readers have prior knowledge of the topic. This was examined by $\mathrm{Hu}$ and Nassaji (2014) who, using think-aloud protocols, found that one important characteristic of successful lexical inferencers is their frequent use of background knowledge.

In a similar vein, several studies have shown that superior text comprehension can result in lexical inferencing success. For example, investigating the effect of topic familiarity on lexical inferencing and incidental vocabulary learning, Pulido (2000, 2003, 2004, 2007) found that vocabulary gains were initially higher when participants read texts containing more familiar topics. In particular, Pulido (2004) examined the effect of cultural background knowledge on immediate incidental vocabulary gains and found that learners' vocabulary scores were higher after they read culturally familiar texts. In another study, Pulido (2007) reported that participants' lexical inferencing success rate improved when they read texts with more familiar scenarios. Similarly, using a self-report questionnaire, Hammadou (1991) suggested that readers with more knowledge of the topic made fewer incorrect inferences.

In an attempt to identify knowledge sources readers use to deal with new words they encounter while reading, Paribakht and Wesche (1999) argued that familiarity with the theme and topic of text was an important factor for successful lexical inferencing. In their study, a participant who had good knowledge of the topic, inferred more words' meanings correctly. Nassaji (2003: 661) also found that among all knowledge sources, readers' world knowledge was used the most to infer the meaning of unfamiliar words; more specifically, he noted that "this knowledge provided an important knowledge base for their judgments". Thus, research indicates that L2 readers' background knowledge significantly contributes to their lexical inferencing success.

\subsection{Limitations of the previous studies}

Although previous research indicates that availability of contextual clues and familiarity with text topic affect the success rate of lexical inferencing, most studies reviewed above have not examined how well the inferred words are retained over time. In addition, the results of few studies examining word retention rate are inconclusive. For example, Li (1988) reported that the retention rate was high only when words were presented in semanticallyrich sentences. However, both Mondria and Wit-de Boer (1991) and Bengeleil and Paribakht (2004) reported that the presence of an unknown word in rich-contextual-clues contexts did 
not necessarily lead to better remembering of that word. Likewise, Pulido $(2000,2003)$ reported that topic familiarity had a positive effect on lexical inferencing although its effect disappeared over time. Another limitation of previous research lies in their lack of interest to consider factors which lead readers to make incorrect lexical inferences. Thus, motivated by inconsistencies and limitations in the previous studies, the present study examines retention of the inferred words' meanings over time, and using think-aloud protocols, investigates factors contributing to unsuccessful lexical inferencing.

\section{The STUDY}

The following questions are addressed in the present study:

1. What is L2 readers' lexical inferencing success rate?

2. Does the amount of context and topic familiarity influence lexical inferencing?

3. To what extent are the inferred words retained immediately and after two weeks?

4. Which factors explain inaccurate lexical inferencing?

\subsection{Method}

\subsubsection{Participants}

Participants in this study were 67 (selected from a pool of 180) female low-intermediate English language learners at a private language institute in Iran. Their ages ranged from 20 to 40 years. Of all 67 participants who were met twice during the study (for immediate and delayed post-tests), 10 took part in think-aloud protocols after they completed the delayed post-test.

\subsubsection{Reading Texts}

To ensure that learners would reach $98-95 \%$ lexical coverage for successful comprehension and lexical inferencing, texts were selected from graded readers (Laufer \& RavenhorstKalovski, 2010). Four short expository texts (cue-adequate contexts) including 7 or 8 target words per text (30 in total) were selected from graded readers' short story book to examine participants' lexical inferencing behavior. Of the four selected texts, two texts had topics and scenarios that were more familiar to the participants, and two had less familiar topics. Of the 30 target words, 15 occurred in texts with familiar topics and 15 in texts with less familiar topics. According to Nation (2001) the ratio of known to unknown words should be considered in lexical inferencing process. In texts with high density of unknown words, learners will not be able to make correct guesses. To ensure that the selected texts were suitable for participants at the low-intermediate level of English proficiency, Flesch Reading Ease Measure was used to compare readability of the selected texts with those from the English book they were studying at the institute. The results indicated that the selected texts were similar to those in their textbooks in terms of the level of difficulty. 


\subsubsection{Single sentences}

Thirty single sentences (cue-inadequate contexts), with one target word per sentence, were selected from the graded readers for lexical inferencing purpose. All single sentences were numbered and presented on one page.

\subsubsection{Target words}

A target of 60 words were underlined in texts and single sentences to examine the effect of different context types on lexical inferencing success rate and the retention of word meaning over time. The target words, a combination of nonwords and real English words, were presented in texts (cue-adequate contexts) and single sentences (cue-inadequate contexts). Target words in the cue-adequate contexts were surrounded by some clues, whereas, in single sentences, each target word was embedded in a very short, contextneutral sentence.

\subsubsection{Vocabulary tests}

Participants' knowledge of the inferred words was assessed immediately and after two weeks by a multiple-choice test in the form of meaning recognition test. Each target word was followed by three distractors and one correct response. The reliability of the test was .84 , suggesting stability of the measure.

\subsubsection{Procedures}

The present study was conducted in two phases. In phase one (piloting phase), materials were piloted to see which target words and text topics were more/less familiar to the participants and how much time they needed to make inferences. In phase two, the main study was conducted. First, participants were presented with a topic familiarity questionnaire on reading texts and a pre-test on target words (Appendix A). The purpose was to make sure that text topics and target words were unfamiliar to all participants. Participants who reported to have some knowledge of the target words/topics were excluded from the study; thus, 67 language learners (out of 180) took part in the next phase. They were asked to read the texts and sentences, infer the meaning of the underlined words, and write their meanings in English below each item (60 words in total). One point was awarded to each correctly inferred word, resulting in a maximum score of 30 for single sentences and 30 for the texts. Later, their knowledge of the inferred words was assessed by means of multiplechoice post-tests immediately and after two weeks (Appendix B). The meaning recognition test was scored by giving one point to each correctly inferred item, yielding in a maximum score of 60 . Finally, 10 participants were requested to think-aloud the meaning of the unknown words they had inferred incorrectly and say out loud what strategies they employed to make inferences (Appendix C). 


\section{RESUlts AND DisCUSSION}

\subsection{Lexical inferencing success rate}

As for L2 lexical inferencing success, it was found that participants could correctly infer the meaning of target words $72.23 \%$ of the time from cue-adequate contexts (texts) and $39.3 \%$ of the time form cue-inadequate contexts (single sentences), yielding an average rate of $55.76 \%$. This is almost in line with the results reported in previous studies (e.g., Bengeleil \& Paribakht, 2004; Hu \& Nassaji, 2012; Huckin \& Bloch, 1993; Pulido, 2007; Morrison, 1996). Therefore, it can be concluded that lexical inferencing helps readers, almost in half of the cases, to find out the meaning of unfamiliar words without consulting a dictionary.

\subsection{Contributions of contextual clues and topic familiarity to lexical inferencing suc- cess rate}

The results pointed to differences in lexical inferencing success rate in cue-adequate and cue-inadequate contexts (Table 1). Of the 30 target words presented in cue-adequate contexts, participants inferred $72.23 \%$ correctly, while of the 30 target words in cue-inadequate contexts, only $39.3 \%$ were inferred correctly. The paired-samples $t$-test results revealed that this difference was significant: $t(66)=16.64, p<.001$, implying that the presence of target words in rich-clue contexts enables participants to arrive at the meaning of these words more successfully.

Table 1. Lexical Inferencing Success in Cue-adequate and Cue-inadequate Contexts

\begin{tabular}{|l|c|c|c|c|c|c|}
\hline Context & Max score & Min score & Raw score & Mean & SD & \% Correct \\
\hline Cue-adequate & 28 & 13 & 30 & 21.67 & 4.03 & 72.23 \\
\hline Cue-inadequate & 18 & 8 & 30 & 11.79 & 2.71 & 39.3 \\
\hline
\end{tabular}

Lexical inferencing was also influenced by topic familiarity. Participants correctly guessed $85 \%$ of target words from texts with familiar topics and $59.53 \%$ of target words from the texts with less familiar topics (Table 2). The paired-samples $t$-test results indicated that lexical inferencing scores on more familiar topics were significantly higher $t(66)=15.35$, $p<.001$, implying that topic familiarity significantly influences lexical inferencing success.

Table 2. Lexical Inferencing Success in Cue-adequate Contexts with Familiar and Less Familiar Topics

\begin{tabular}{|l|c|c|c|c|c|c|}
\hline Cue-adequate contexts & Max score & Min score & Raw score & Mean & SD & \% Correct \\
\hline Familiar topics & 15 & 8 & 15 & 12.75 & 1.96 & 85 \\
\hline Less Familiar topics & 13 & 4 & 15 & 8.93 & 2.52 & 59.53 \\
\hline
\end{tabular}


Overall, it was found that the availability of contextual clues and readers'familiarity with text topics significantly influence their success in lexical inferencing. Findings regarding the contribution of contextual clues to accurate inferences are in line with those of previous studies in the literature (e.g., Çetinavc1, 2014; Mondria \& Wit-de Boer, 1991; Li, 1988). These results are also consistent with the findings of studies discussed earlier (e.g., Hammadou, 1991; Pulido, 2004; 2007), suggesting that texts with familiar topics can activate more background knowledge, thus enabling readers to make more correct inferences. Pedagogically, findings highlight that if lexical inferencing is to be taught, it might best be practiced in texts with familiar themes and sufficient contextual clues.

\subsection{Immediate and delayed post-tests}

The third research question examined how many inferred words could be retained immediately after reading and over a period of two weeks. The results showed that readers could retain the meaning of $46 \%$ and $31.3 \%$ of target words immediately and after two weeks, respectively. The paired-samples $t$-test results showed that the difference between the immediate and delayed post-test scores was significant: $t(66)=24.07, p<.001$, suggesting that word meaning retention had decreased after two weeks (Table 3 ).

Table 3. Lexical Inferencing in the Immediate and Delayed Posttests

\begin{tabular}{|l|c|c|c|c|c|c|}
\hline Post-tests & Max score & Min score & Raw score & Mean & SD & \% Correct \\
\hline Immediate & 40 & 11 & 60 & 27.60 & 8.57 & 46 \\
\hline Delayed & 33 & 5 & 60 & 18.78 & 8.52 & 31.3 \\
\hline
\end{tabular}

When the effect of context on retention of the inferred word meanings was examined, $t$-test results indicated that words in cue-adequate contexts were remembered better than those in cue-inadequate contexts, both on the immediate $t(66)=14.35, p<.00$, and delayed post-tests $t(66)=12.26, p<.00$ (Table 4$)$.

Table 4. Lexical Inferencing in Cue-adequate and Cue-inadequate Contexts

\begin{tabular}{|l|l|c|c|c|c|c|c|}
\hline \multirow{2}{*}{$\begin{array}{l}\text { Immediate } \\
\text { post-test }\end{array}$} & $\begin{array}{l}\text { Cue- } \\
\text { adequate }\end{array}$ & 30 & 15 & 30 & 23.09 & 5.70 & 76.96 \\
\cline { 2 - 8 } & $\begin{array}{l}\text { Cue- } \\
\text { inadequate }\end{array}$ & 21 & 6 & 30 & 14.66 & 4.04 & 46.88 \\
\hline \multirow{2}{*}{$\begin{array}{l}\text { Delayed } \\
\text { post-test }\end{array}$} & $\begin{array}{l}\text { Cue- } \\
\text { adequate }\end{array}$ & 23 & 5 & 30 & 15.06 & 5.40 & 50 \\
\cline { 2 - 8 } & $\begin{array}{l}\text { Cue- } \\
\text { inadequate }\end{array}$ & 18 & 3 & 30 & 8.72 & 4.01 & 29.06 \\
\hline
\end{tabular}


Furthuremore, $t$-test results for the effect of topic familiarity on the immediate post-test showed that words presented in texts with familiar topics had better chance of being retained than those presented in less familiar texts, $t(66)=9.87, p<.00$. However, no topic familiarity effect was observed on the delayed post-test scores, $t(66)=1.69, p=.09$ (Table 5).

Table 5. Lexical Inferencing in Texts withFamiliar and Less Familiar Topics

\begin{tabular}{|l|l|c|c|c|c|c|c|}
\hline \multirow{2}{*}{$\begin{array}{l}\text { Immediate } \\
\text { post-tests }\end{array}$} & Max score & Min score & Raw score & Mean & SD & $\%$ Correct \\
\cline { 2 - 8 } & Familiar topics & 15 & 10 & 15 & 13.90 & 1.73 & 92.66 \\
\hline \multirow{2}{*}{$\begin{array}{l}\text { Delayed } \\
\text { post-test }\end{array}$} & Fess familiar topics & 15 & 2 & 15 & 9.27 & 4.53 & 61.8 \\
\cline { 2 - 8 } & Fess familiar topics & 12 & 2 & 15 & 7.72 & 2.69 & 51.46 \\
\hline
\end{tabular}

Overall, findings revealed that readers learned the meanings of some new words immediately through lexical inferencing. However, this gain was not durable over time. This is in line with the findings of Haastrup (1991), Mondria and Wit-de Boer (1991), Bengeleil and Paribakht (2004), and Pulido $(2000,2003)$ who reported that inferring the meaning of a new word does not necessarily lead to its retention. Also, the findings are in agreement with those of Brown, Waring and Donkaewbua (2008), Chen and Truscott (2010), Waring and Takaki (2003) who, utilizing delayed post-tests, observed that readers' knowledge of the newly learned vocabulary items declined over time. As stated by Nation (2001: 236), "this might be partly due to poor design, but it is also the effect of the cumulative nature of such learning involving only small gains per meeting for most words". Thus, the decline in retention of the inferred words' meanings may be due to the fact that target words were presented only once in the text or lack of learners' exposure to those words in other contexts. Interestingly, this is echoed by Waring and Takaki (2003) who argued that vocabulary learning is a cumulative process in that learners build up knowledge of a word through repeated encounters. Another possible explanation for the decline in retention rate is that participants did not receive any feedback after their lexical inferencing attempts; therefore, they did not have a chance to verify the inferred meanings. Haastrup (1991) remarked that giving feedback to readers during inferencing would lead to better word retention. In spite of the above-mentioned factors, readers in the present study could retain $31.3 \%$ of the inferred target words successfully after two weeks from a single exposure to those words. This shows that lexical inferencing leads to learning previously unfamiliar words to some extent. This is confirmed by Bengeleil and Paribakht (2004: 241) who noted that "the inferencing task made the target words more salient to the participants and brought at least some of the words to their attention". Furthermore, in the present study, it was found that the presence of unknown words in texts with rich contextual clues led to better remembering of their meaning both immediately and after two weeks. Topic familiarity also had a positive effect on the immediate post-test though its effect disappeared over time. This can support the role of contextual clues in vocabulary learning. An implication of these findings is that lexical inferencing should be practiced on a regular basis under teachers' supervision. L2 learners need to receive instruction on how to use the context of reading, their background knowledge, and lexical inferencing strategies to make correct inferences. 


\subsection{Factors leading to incorrect lexical inferencing}

To address the fourth research question, the participants were presented with the target words that they had inferred incorrectly and were asked to report on how they arrived at incorrect meanings. A closer examination of what led them to make inaccurate lexical inferences suggests the following:

a) Using local contextual clues: there were 8 words which were inferred inaccurately because of using local clues in the context. Usually, when readers encounter unknown words, they use available cues and key words around the unknown words in order to find a plausible meaning for them. Here, the readers did the same; however, as pointed out earlier in the literature, the context can sometimes be misleading. For example, the word hatch in the sentence 'the eggs take three days to hatch' was inferred incorrectly as to expire. This seemed a logical inference for the readers as the sentence made sense when hatch was replaced with expire. This appears to explain one of the drawbacks of using contextual clues to infer the meaning of unknown words.

b) Confusing new words with the ones that look similar: six words were inferred inaccurately because of having the same visual form as other English words. For example, the word threatened was confused by treated.

c) Analyzing compound words into their constituents: five words were inferred inaccurately because learners divided unknown words into their constituent parts. For example, some learners noted that they divided encouragement into three syllables: en + courage + ment. Being familiar with the meaning of courage and not knowing the function of 'en', they were misled to interpret it as 'a brave person'.

These findings are consistent with the previous research (Bensoussan \& Laufer, 1984; Dubin \& Olshtain, 1993; Haynes, 1993; Hulstijn, 1992; Laufer, 1997), suggesting that the context and word form could misguide readers in the inferencing task. However, it should be noted that factors which encouraged readers to make inaccurate lexical inferencing are part of strategies and knowledge sources that can assist readers in deriving word meaning from context. Thus, it seems that, by making readers aware of effective use of strategies and knowledge sources in lexical inferencing task, they can use these strategies more efficiently in future.

\section{CONClusions, LIMitations AND SUgGESTIONS FOR FURTHER RESEARCH}

The first important conclusion of the present study is that Iranian EFL low-intermediate language learners successfully inferred, in more than half of the cases, the meaning of unfamiliar words while reading. Secondly, successful lexical inferencing rate depends on the amount of contextual cues (cue-adequate contexts $>$ cue-inadequate contexts) in texts and the level of readers' familiarity with the text topic (more familiar topics $>$ less familiar topics). Thirdly, the learners in the present study could retain $46 \%$ and $31.3 \%$ of the target words immediately and after two weeks, respectively. Next, although the effect of context on retention of the meaning of new words lasted for two weeks, the effect of topic familiarity decreased significantly. Finally, this study suggests three possible explanations for inaccurate decisions about the meaning of the unknown words. 
Although this study provided insights into lexical inferencing strategy use, there were a number of limitations that should be taken into consideration in future studies. First, in this study target words were presented only once in the text. As repeated exposures to a word would increase chances of its learning, a replication of this study with more exposures to target words can yield different results. Second, only contextual clues and topic familiarity were examined in this study. There are other factors influencing lexical inferencing such as readers' working memory and their L2 vocabulary knowledge which can be explored in further research. Third, readers in the present study did not receive any prior explicit instruction on lexical inferencing, nor did they receive any feedback after their inferencing attempts. Therefore, a follow-up study might be conducted by presenting readers with inferencing instruction and providing them with feedback or asking them to consult a dictionary to verify their inferences to investigate how the uptake rate might vary. Next, think-aloud protocols of only 10 participants were used to find out how they were misdirected by contextual factors. To arrive at more generalizable conclusions, studies with more participants are required. Finally, this study used meaning recognition tests which measured only one dimension of vocabulary knowledge. In order to get a more complete view of vocabulary learning through lexical inferencing, various dimensions of vocabulary knowledge should be measured.

\section{REFERENCES}

Alcaraz-Mármol, G. (2015). "Dispersion and frequency: Is there any difference as regards their relation to L2 vocabulary gains?" in International Journal of English Studies, 15, 2: 1-16.

Barnett, M. (1989). More than Meets the Eye. Englewood Cliffs, NJ: Prentice Hall.

Bengeleil, N.F., \& Paribakht,T.S.(2004). "L2 reading proficiency and lexical inferencing by university EFL learners", in The Canadian Modern Language Review, 61, 2: 225-249.

Bensoussan, M., \& Laufer, B. (1984). "Lexical guessing in context in EFL reading comprehension", in Journal of Research in Reading, 7, 1: 15-32.

Brown, R., Waring, R., \& Donkaewbua, S. (2008). "Incidental vocabulary acquisition from reading, reading-while-listening, and listening". Reading in a Foreign Language, 20, 136-63.

Cetinavci, B.M. (2014). "Contextual factors in guessing word meaning from context in a foreign language", in Social and Behavioral Science, 116, 2670-2674

Chern, C. L. (1993). "Chinese students' word-solving strategies in reading in English", in T. Huckin, Haynes, M., \& J. Coady (eds.), Second Language reading and Vocabulary Learning (pp. 67-85). Norwood, NJ: Ablex.

Chen, C. \& Truscott, J. (2010). "The effects of repetition and L1 lexicalization on incidental vocabulary acquisition". Applied Linguistics, 31, 693-713.

Comer, J. William (2012). "lexical inferencing in reading L2 Russian" in Reading in a foreign language, 24, 209-203.

DeBot. K., Paribakht, T.S., \&Wesche , M. B. (1997). "Toward a lexical processing model for the study of second language vocabulary acquisition", in Studies in Second Language Acquisition, 19, 309-329.

Dubin, F., \& Olshtain, E. (1993). "Predicting word meanings from contextual clues: Evidence from L1 readers", in T. Huckin, M. Haynes, \& J. Coady (eds.), Second Language Reading and Vocabulary Learning (pp. 181-202). Norwood, NJ: Ablex. 
Frantzen, D. (2003). "Factors affecting how second language Spanish students derive meaning from context", in Modern Language Journal, 87, 2: 168-199.

Fraser, C. A. (1999). "Lexical processing strategy use and vocabulary learning through reading", in Studies in Second Language Acquisition, 21, 225-241

Haastrup, K. (1991). Lexical inferencing procedures, or talking about words: Receptive procedures in foreign language learning with special reference to English. Tübingen, Germany: Gunter Narr.

Hammadou, J. (1991). "Interrelationships among prior knowledge, inference, and language proficiency in foreign language reading", in The Modern Language Journal, 75, 27-38.

Haynes, M. (1993). "Patterns and perils of guessing in second language reading", in T. Huckin, M. Haynes and J. Coady (eds.), Second Language Reading and Vocabulary Learning. Norwood, NJ: Ablex, 46-62.

Hu, H.C., Nassaji, H. (2012). "Ease of inferencing, learner inferential strategies, and their relationship with the retention of word meanings inferred from context", in Canadian Modern Language Review, 68, 1: 54-77.

Hu, H. M. (2013). "The effect of word frequency and contextual types on vocabulary acquisition from extensive reading: A case study", in Journal of Language Teaching and Research, 4, 3: 487-495.

Hu, H. M. \& Nassaji, H. (2014). "Lexical inferencing strategies: the case of successful versus less successful inferencers" in System, 45, 27-38.

Laufer, B., \& Ravenhorst-Kalovski, G. C. (2010). "Lexical threshold revisited: Lexical coverage, learners' vocabulary size and reading comprehension", in Reading in a Foreign Language, 22, 1: 15-30.

Huckin, T., \& Bloch, J. (1993). "Strategies for inferring word meanings: A cognitive model", in T. Huckin, M. Haynes, \& J. Coady (eds.), Second Language Reading and Vocabulary Learning (pp. 153-178). Norwood, NJ: Ablex.

Hulstijn, J. H. (1992). "Retention of inferred and given word meanings: Experiments in Incidental vocabulary learning",, in P.J.L. Arnaud and H. Bejoint (eds.), Vocabulary and Applied Linguistics. London: Macmillan, 113-25.

Kaivanpanah, S., \& Alavi, S. M. (2008a). "Deriving unknown word meaning from context: Is it reliable?", in RELC Journal, 39,1: 77-95.

Kaivanpanah, S., \& Alavi, S. M. (2008b). "The role of linguistic knowledge in word meaning inferencing" in System, 36, 172-195

Laufer, B. (1997). "The lexical plight in second language reading: Words you don't know, words you think you know, and words you can't guess", in J. Coady \& T. Huckin (eds.), Second language vocabulary acquisition: A rationale for pedagogy (pp. 20-34). Cambridge: Cambridge University Press

Li, X. (1988). "Effects of contextual cues on inferring and remembering meanings of new words", in Applied Linguistics, 9, 402-413.

Liu, N., \& Nation, I.S.P. (1985). "Factors affecting guessing vocabulary in context", in, RELC Journal, 16, 1: 33-42.

Mondria, J.A., \& M. Wit-de Boer. (1991). "The effects of contextual richness on the guessability and the retention of words in a foreign language", in Applied Linguistics, 12, 249-67.

Nassaji, H. (2002). "Schema theory and knowledge-based processes in second language reading comprehension: A need for alternative perspectives", in Language Learning, 52, 2: 439-481.

Nassaji, H. (2003). "L2 vocabulary learning from context: Strategies, knowledge sources, and their relationship with success in L2 lexical inferencing", in TESOL Quarterly, 37, 645-670. 
Nassaji, H., \& Hu, H. C. M. (2012). The relationship between task-induced involvement load and learning new words from context. International Review of Applied Linguistics in Language Teaching, 50(1), 69-86.

Nation, I. S. P. (2001). Learning vocabulary in another language. Cambridge: Cambridge University Press.

Morrison, L., (1996). "Talking about words: a study of French as a second language learners' lexical inferencing procedures", in The Canadian Modern Language Review, 53, 41-75.

Paribakht, T.S. (2004). "The role of Grammar in second language learning Processing", in RELC, 35, 2: $149-160$.

Paribakht, T. S. (2005). "The influence of L1 lexicalization on L2 lexical inferencing: A study of Farsi-speaking EFL learners", in Language Learning, 55,701-748.

Paribakht, T. S., \& Wesche, M. (1999). "Reading and incidental L2 vocabulary acquisition: An introspective study of lexical inferencing", in Studies in Second Language Acquisition, 21, 195-224.

Parry, K. (1993). "Too many words: Learning the vocabulary of an academic text", in T. Huckin, M. Haynes, \& J. Coady (eds.), Second language reading and vocabulary learning (pp. 109-129). Norwood, NJ: Ablex.

Pulido, D. (2000). The impact of topic familiarity, L2 reading proficiency, and L2 passage sight vocabulary on incidental vocabulary gain through reading for adult learners of Spanish as a foreign language. Unpublished Doctoral dissertation, University of Illinois at UrbanaChampaign, Michigan, U.S.A.

Pulido, D. (2003). "Modeling the role of second language proficiency and topic familiarity in second language incidental vocabulary acquisition through reading", in Language Learning, 53, 233-284.

Pulido, D. (2004). "The effect of cultural familiarity on incidental vocabulary acquisition through reading", in The Reading Matrix, 4, 20-53.

Pulido, D. (2007). "The effects of topic familiarity and passage sight vocabulary on L2 lexical inferencing and retention through reading", in Applied Linguistics, 28, 66-86.

Qian, D. D. (2005). "Demystifying lexical inferencing: the role of aspects of vocabulary knowledge", in TESL Canada Journal, 22, 34-54.

Tavakoli, M., \& Gerami, E. (2013). "The Effect of Keyword and pictorial methods on EFL learners' vocabulary learning and retention", in Porta Linguarum, 19, 299-316.

Waring, R., \& Takaki, M. (2003). "At what rate do learners learn and retain new vocabulary from reading a graded reader?" in Reading in a Foreign Language, 15, 130-63.

Wesche, M., Paribakht, T.S. (2010). Lexical inferencing in a first and second language: Crosslinguistic dimensions, Clevedon, UK: Multilingual Matters 


\section{Appendices}

Appendix A: Example of topic familiarity questioner and target words pre-test.

1. Are you familiar with this topic? please circle Yes or No

2. Please write as much as you know about this topic....

3. Do you know the meaning of this word ....? Write its meaning in English

Appendix B: Examples of multiple-choice meaning recognition test used for the immediate and delayed post-tests Select one of the five options. Only one is the correct definition. If you do not know the meaning of the word, please select option "e".

1. Disappointed
a) hopeless
b) hungry
c) cheerful
d) bored
e) don't know

2. Profession
a) Baby
b) $\mathrm{Car}$
c) Job
d) Favor
e) don't know

3. Gathered
a) Hit
b) Came together
c) Bought
d) Ate
e) don't know

4. Immune
a) Safe
b) Dangerous
c) Contagious
d) Infectious
e) don't know

5. Feasible
a) impossible
b) movable
c) edible
d) possible
e) don't know 


\section{Appendix C: Examples of prompt questions for the interview.}

1. Do you know the meaning of this word (for example encouragement!)?

2. Why do you think this word means ......? Please explain!/ Could you please explain how did you arrive at this meaning?

3. What encouraged you to get to this inferencing?

4. Can it have a different meaning in this sentence? 